PENELITIAN

\title{
Perbandingan Visualisasi Laring dan Glotis pada Maneken Intubasi Sulit menggunakan Video Laryngoscope C-MAC dan VL-Scope
}

\section{Comparison of Larynx and Glottic Visualization in Difficult Intubation Mannequin using Video Laryngoscope C-MAC and VL-Scope}

\author{
Abdul Kadir Munsy ${ }^{\bowtie}$, Nancy Margarita Rehatta, Maulydia, Agustina Salinding, Arie \\ Utariani, Teguh Sylvaranto, Elizeus Hanindito \\ Departemen/ SMF Anestesiologi dan Reanimasi, Fakultas Kedokteran, Universitas Airlangga/ \\ RSUD Dr. Soetomo, Surabaya, Indonesia \\ ${ }^{\bowtie}$ Korespondensi : Abdulkadirmunsy@gmail.com
}

\begin{abstract}
Background: C-MAC video laryngoscope has proven to be very helpful during intubation, especially in patients with difficult airway. Anesthesiology and Reanimation Department of Dr. Soetomo Hospital in Surabaya has created a VL-Scope video laryngoscope with features that can record audiovisual at a much cheaper price.

Objective: To compare the time required by C-MAC and VL-Scope video laryngoscopes on a mannequin simulation of rigid cervical spine immobilization collar neck.

Methods: The research method was an experimental randomized design group involving residents to intubate with 2 video laryngoscopes namely C-MAC and VL-Scope on a mannequin simulation of cervical spine immobilization with rigid collar neck. The study was conducted by observing the difference in time needed to see plica vocalis, length of intubation and dental injury using C-MAC laryngoscope and VL-Scope video laryngoscope.

Results: C-MAC video laryngoscope study shortened the average time to assess the degree of Cormarck and Lehane (8.57 \pm 2.64$)$ and intubation (17.89 \pm 5.92$)$ compared to VL-Scope video laryngoscope (12.24 \pm 5.83$)$ and (20.68 \pm 5.83$)$ seconds. However, the incidence of suppression of teeth during laryngoscopy was the same using both devices 2/37 (5.4\%).

Conclusion: Intubation using C-MAC video laryngoscopes was more effective in maneuvers immobilization of cervical spine with rigid collar neck but the incidence of dental injury in both actions are the same.
\end{abstract}

Keywords: cervical neck immobilization; intubation; mannequin; video laryngoscope 


\begin{abstract}
ABSTRAK
Latar Belakang: Video laryngoscope C-MAC terbukti sangat membantu dalam tindakan intubasi terutama pada pasien kasus dengan difficult airway. Departemen Anestesiologi dan Reanimasi Rumah Sakit Dokter Soetomo Surabaya telah menciptakan video laryngoscope VL-Scope dengan fitur perekam audiovisual dengan harga yang jauh lebih murah.
\end{abstract}

Tujuan: Membandingkan waktu yang dibutuhkan oleh video laryngoscope C-MAC dan VL-Scope pada simulasi maneken imobilisasi cervical spine dengan rigid collar neck.

Metode: Penelitian dengan desain eksperimental acak ini melibatkan residen untuk melakukan intubasi dengan 2 video laringoskop yaitu C-MAC dan VL-Scope pada simulasi maneken imobilisasi cervical spine dengan rigid collar neck. Penelitian dilakukan dengan cara mengobservasi perbedaan waktu yang diperlukan untuk melihat plica vocalis, lama intubasi dan penekanan pada gigi menggunakan laringoskop C-MAC dan video laringoskop VL-Scope

Hasil: Video laryngoscope C-MAC mempersingkat waktu rata-rata untuk menilai derajat Cormarck and Lehane $(8.57 \pm 2,64)$ dan intubasi $(17.89 \pm 5,92)$ dibandingkan dengan video laringoskop VL-Scope $(12.24 \pm 5,83)$ dan $(20,68 \pm 5,83)$ detik. Namun frekuensi kejadian penekanan terhadap gigi saat tindakan laringoskopi adalah sama menggunakan kedua alat tersebut 2/37(5,4\%)

Kesimpulan: Intubasi menggunakan video laryngoscope C-MAC lebih efektif pada maneken imobilisasi cervical spine dengan rigid collar neck namun angka kejadian penekanan gigi pada tindakan tersebut adalah sama.

Kata kunci: imobilisasi cervical neck; intubasi; maneken; video laryngoscope

\section{PENDAHULUAN}

Maneken luas digunakan untuk melatih beberapa keahlian yang diperlukan oleh tenaga kesehatan. Maneken memiliki berbagai desain dan perlakuan yang disesuaikan dengan skenario untuk melatih keahlian yang diperlukan khususnya digunakan pada prosedur yang tidak rutin seperti kondisi trauma cervical sehingga harus dilakukan imobilisasi cervical spine dengan collar neck yang merupakan salah satu penyebab difficult airway., ${ }^{1,2}$ Dalam hal ini penggunaan maneken sebagai media pembelajaran memiliki keuntungan dalam melatih keahlian yang dibutuhkan seorang anestesi. ${ }^{3}$

Penelitian prospektif observasional sejak 1 Januari 2000 sampai 31 Desember 2006 pada 2343 pasien dimana 93 (4\%) mengalami situasi difficult airway disebabkan laring anterior 38 (40,9\%), neck immobility 22 (23.7\%) sekret dan darah 14 (15.1\%). ${ }^{4}$ Neck immobilty yang menjadi salah satu penyebab terjadinya difficult airway pada penelitian tersebut memiliki angka kejadian yang tinggi. Dalam hal ini maneken sebagai media pembelajaran memiliki peran penting dalam melatih peserta didik ketika mendapat kondisi tersebut. $5,6,7$

Video laryngoscope C-MAC terbukti lebih unggul dalam usaha pertama intubasi pada imobilisasi Cervical Spine dengan collar neck dibandingkan Macintosh Laryngoscope, McCoy blade, dan D-Blade Video laryngoscope $C$ $M A C$ pada maneken simulasi cervical spine yang dilakukan oleh residen 
anestesi. ${ }^{8}$

Salah satu usaha yang telah dilakukan oleh Departemen Anestesi dan Reanimasi Surabaya adalah menghasilkan alat video laryngoscope sendiri, yaitu VL-Scope. ${ }^{2,9}$ Dengan adanya alat ini, diharapkan selain memudahkan intubasi, juga dapat menekan tingginya pengeluaran akibat membeli peralatan impor untuk intubasi, serta diharapkan dapat dipergunakan di rumah sakit - rumah sakit daerah di seluruh Indonesia. Video laryngoscope VL-Scope ini dalam prakteknya seharihari telah digunakan pada tindakan intubasi rutin, namun belum ada penelitian mengenai perbedaan waktu intubasi menggunakan VL-Scope ini dibanding dengan video laryngoscope $\mathrm{C}$ MAC Pada keadaan imobilisasi cervical spine dengan rigid collar neck yang dilakukan oleh peserta pendidikan dokter spesialis tahap 3 Departemen Anestesi. ${ }^{8,9,10,11}$

\section{METODE}

Penelitian ini merupakan penelitian acak eksperimental yang dilakukan pada bulan Maret 2018 di ruang pemulihan Gedung Bedah Pusat Terpadu RSUD Dr. Soetomo sampai memenuhi jumlah sampel pada kedua alat laringoskop.

Penelitian ini diikuti oleh tiga puluh tujuh peserta didik tahap mandiri atau tahap akhir dalam pendidikan di Departemen Anestesi Fakultas Kedokteran Universitas AirlanggaRSUD Dr. Soetomo Surabaya yang dipilih secara acak serta setuju mengikuti penelitian ini dengan mengisi lembar keikutsertaan penelitian.

Alat intubasi yang dibandingkan ialah (Gambar 1):

(1) Storz C-MAC video laryngoscope, size 3 (Karl Storz GmbH, Tuttlingen, Germany); (2) VL-Scope Video laryngoscope, Size 3 (Anestesi Surabaya, Nomor hak cipta C00201605810).

Semua tindakan intubasi menggunakan tracheal tube dengan ukuran $7.0 \mathrm{~mm}$ dengan cuff. Semi-rigid stylet yang dibentuk hockey shape $(8 \mathrm{~mm}$ dari ujung stylet dibentuk hingga 100 derajat) untuk kedua video laryngoscope C-MAC dan VL-Scope. Pelumas Laerdal Medical ${ }^{\circledR}$ dan spuit $20 \mathrm{ml}$ digunakan untuk mengembangkan cuff pada tracheal tube. Ambu bag disiapkan pada penelitian ini.

Setiap residen yang terlibat dalam penelitian ini melakukan intubasi menggunakan kedua video laryngoscope C-MAC dan VL-Scope pada maneken Laerdal Airway Trainer $^{\circledR}$ dengan skenario imobilisasi cervical spine menggunakan rigid collar neck (Ambu, Perfit Collar $^{\circledR}$ ). Sebelum memulai tindakan laringoskopi peserta diminta mengambil amplop tertutup dengan tujuan memilih urutan penggunaan video laryngoscope dan mengurangi bias dalam penggunaan video laryngoscope tersebut, selama tindakan laringoskopi hingga intubasi peserta dibantu seorang asisten. Hasil yang diukur dalam penelitian ini adalah: (1) lamanya waktu yang diperlukan untuk melihat plica vocalis dan glotis (derajat Cormack dan Lehane); (2) waktu yang diperlukan untuk intubasi hingga ventilasi; (3) jumlah kegagalan intubasi pada kesempatan pertama; dan (4) jumlah kejadian penekanan gigi berlebihan saat laringoskopi.

Lama waktu untuk melihat plica vocalis dan glotis adalah waktu yang diperlukan untuk dapat melihat plica vocalis dan glotis sejak video laryngoscope mulai dimasukkan kedalam mulut hingga dapat ditentukan derajat Cormack dan Lehane. 
Waktu yang diperlukan untuk intubasi hingga ventilasi adalah waktu yang diperlukan sejak laryngoscope dimasukkan kedalam mulut hingga tracheal tube dimasukkan ke trakea dan paru dapat diventilasi. Kegagalan intubasi pada kesempatan pertama adalah gagal memasukkan tracheal tube pada trakea dalam 120 detik atau mengeluarkan tracheal tube dari mulut. Kejadian penekanan gigi berlebihan saat
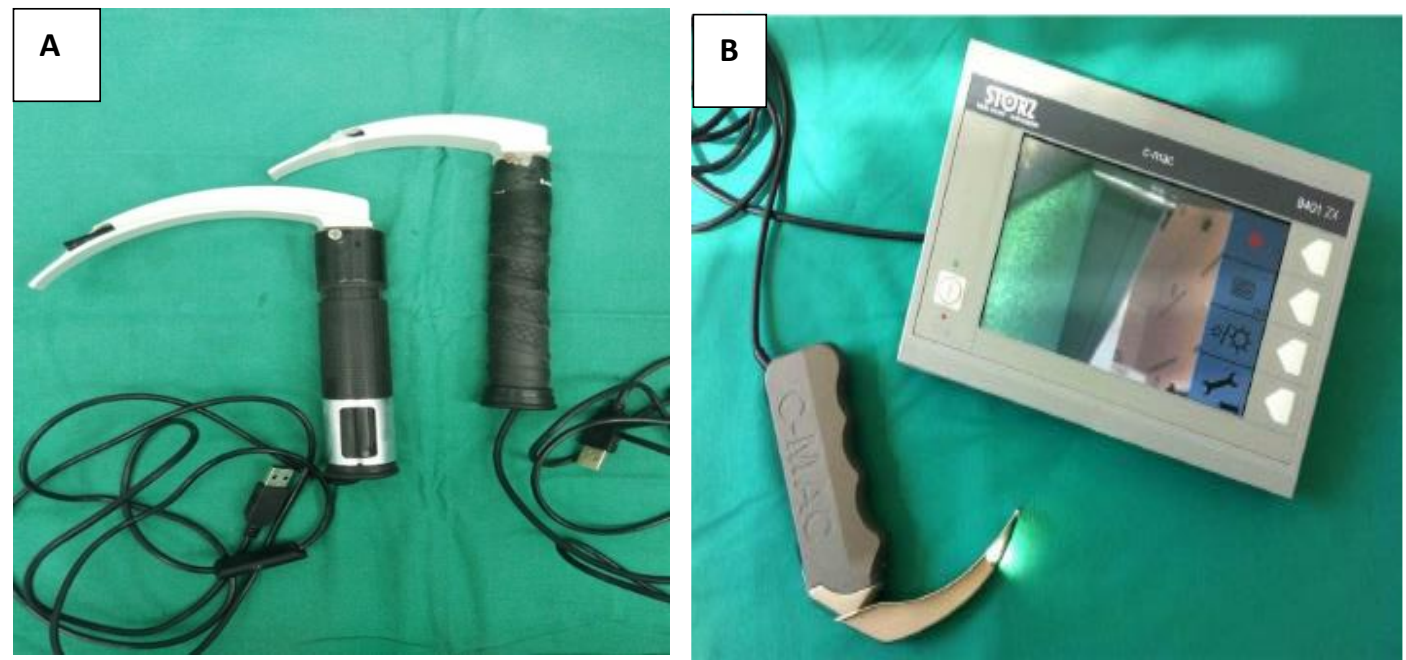

Gambar 1. A. Video laryngoscope VL-Scope B. Video laryngoscope C-MAC

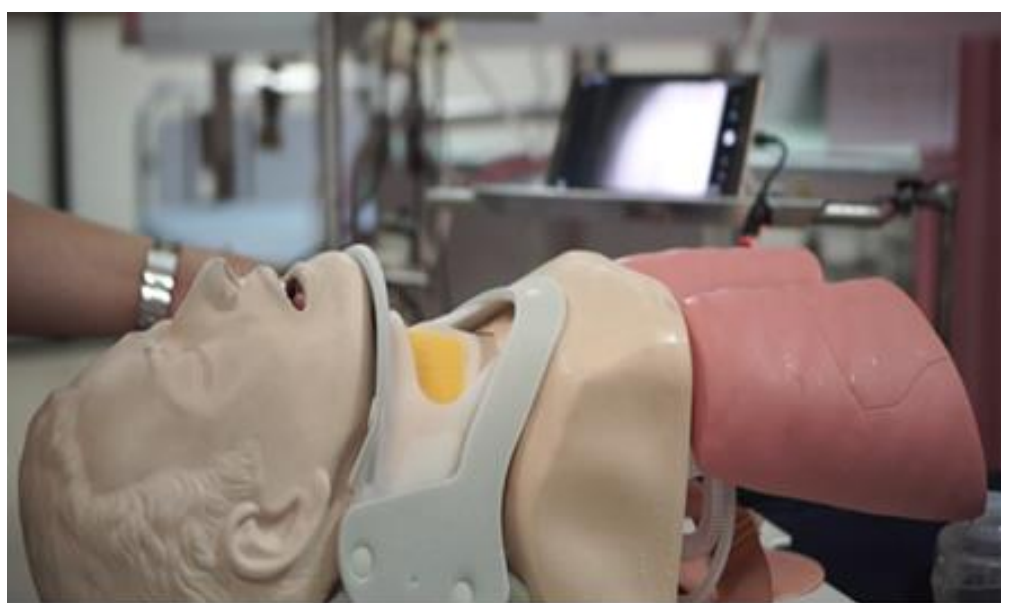

Gambar 2. Maneken imobilisasi cervical Spine dengan rigid collar neck 
HASIL

Pada penelitian ini didapatkan 37 sampel yang memenuhi kriteria inklusi dan eksklusi, dengan hasil data karakteristik laki-laki $26(70.3 \%)$ dan perempuan 11 (29,7\%) yang dipaparkan pada Tabel 1. Data berdasarkan distribusi kelompok usia 20-30 tahun sebanyak $5(13,5 \%)$, $30-40$ tahun $31(83,8 \%)$ dan $>40$ tahun $1(2,7 \%)$. Data tersebut tersaji pada Tabel 2. Dari hasil penelitian didapatkan rata-rata waktu untuk menilai Cormack and Lehane menggunakan video laringoskop C-MAC adalah 8,57 detik dan dengan VL-Scope 12,24 detik. Dari rata-rata tersebut terlihat bahwa rata-rata yang diperlukan untuk melihat Cormarck dan Lehane terpaut 3,67 detik. Data tersebut juga memperlihatkan bahwa rata-rata untuk melakukan intubasi dengan video laringoskop CMAC 17,89 detik dan VL-Scope 20,68 detik. Pada penelitian ini tidak didapatkan angka kegagalan melakukan tindakan intubasi menggunakan kedua laringoskop tersebut sedangkan komplikasi penekanan berlebihan terhadap gigi terjadi 2 kali $(5,4 \%)$ pada masing-masing alat laringoskop. Namun pada penilaian derajat Cormack and Lehane didapatkan Cormack and Lehane 1 pada penggunaan C-MAC sebanyak 3 $(8,3 \%)$ dibanding 0 pada penggunaan VL-Scope, Cormack and Lehane 2 sebanyak $33(89,2 \%)$ pada penggunaan C-MAC dibanding $31(83,8 \%)$ pada VLScope dan Cormack and Lehane 31 $(2,7 \%)$ pada penggunaan C-MAC dan 6 $(16,2 \%)$ pada VL-Scope. Data tersebut disajikan pada Tabel 3.

Tabel 1. Karakteristik jenis kelamin subjek

\begin{tabular}{ccc}
\hline Jenis kelamin & Frekuensi & Persentase (\%) \\
\hline Laki-laki & 26 & 70.3 \\
Perempuan & 11 & 29.7 \\
Total & 37 & 100 \\
\hline
\end{tabular}

Tabel 2. Hasil analisis karakteristik usia

\begin{tabular}{lll}
\hline Variabel & Kategori & Jumlah $(\%)$ \\
\hline Usia & $20-30$ & $5(13,5 \%)$ \\
& $30-40$ & $31(83,8 \%)$ \\
Total & $>40$ & $1(2,7 \%)$ \\
Mean \pm SD & & 37 \\
\hline
\end{tabular}

Tabel 3. Perbandingan C-MAC dan VL-Scope

\begin{tabular}{lllll}
\hline Variabel & C-MAC & VL-Scope & P & Keterangan \\
\hline $\begin{array}{l}\text { Waktu penilaian derajat } \\
\begin{array}{l}\text { Cormack and Lehane } \\
\text { (detik) }\end{array}\end{array}$ & $8.57 \pm 2,64$ & $12.24 \pm 5,83$ & 0,0001 & Bermakna \\
$\begin{array}{l}\text { Waktu intubasi hingga } \\
\text { ventilasi (detik) }\end{array}$ & $17.89 \pm 5,92$ & $20,68 \pm 5,83$ & 0,02 & Bermakna \\
$\begin{array}{l}\text { Kegagalan intubasi (kali) } \\
\text { Ya }\end{array}$ & 0 & 0 & 1,000 & Tidak Bermakna
\end{tabular}




\begin{tabular}{lllll}
$\begin{array}{l}\text { Tidak } \\
\text { Komplikasi penekan gigi } \\
\text { (kali) }\end{array}$ & $37(100 \%)$ & $37(100 \%)$ & 1,000 & Tidak Bermakna \\
Ya & $2(5,4 \%)$ & $2(5,4 \%)$ & & \\
Tidak & $35(94,6 \%)$ & $35(94,6 \%)$ & & \\
$\begin{array}{l}\text { Derajat Cormack and } \\
\text { Lehane (kali) }\end{array}$ & & 0,01 & Bermakna \\
1 & $3(8,1 \%)$ & 0 & & \\
2 & $33(89,2 \%)$ & $31(83,8 \%)$ & & \\
3 & $1(2,7 \%)$ & $6(16.2 \%)$ & & \\
\hline
\end{tabular}

\section{PEMBAHASAN}

Pada penelitian ini waktu rata-rata yang dibutuhkan untuk menilai Cormack and Lehane berbeda bermakna $(\mathrm{p}<0,0001)$, dengan rata-rata waktu untuk melihat Cormack and Lehane menggunakan $\mathrm{C}$ MAC $8.57 \pm 2,64$ detik, dimana waktu tercepat untuk melihat Cormack and Lehane menggunakan video laryngoscope C-MAC adalah 3 detik dan waktu terlama 14 detik. Sedangkan waktu rata-rata untuk melihat Cormack and Lehane menggunakan video laryngoscope VL-Scope 12.24 $\pm 5,83$ detik, dimana waktu tercepat untuk melihat Cormack and Lehane menggunakan video laryngoscope VLScope adalah 6 detik dan waktu terlama 37 detik. Hasil berbeda pada penelitian lain dimana tidak didapatkan perbedaan bermakna $(p>0,05)$ pada hasil uji beda waktu menilai derajat Cormack and Lehane menggunakan video laryngoscope C-MAC dan VL-Scope dengan waktu rata-rata $10,95 \pm 2,16$ detik, dimana waktu tercepat untuk melihat Cormack and Lehane menggunakan video laryngoscope C-MAC 7.3 detik dan waktu terlama 15,10 detik. Sedangkan waktu rata-rata untuk melihat Cormack and Lehane menggunakan

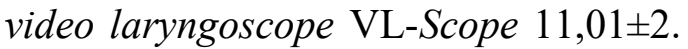
detik, dimana waktu tercepat 8.3 detik dan waktu terlama 15,50 detik. $^{12,13,14,15}$

Penelitian lain menunjukkan, tindakan laringoskopi dengan video Laryngoscope C-MAC dan VL-Scope terhadap penilaian Cormack and Lehane lebih rendah dibanding dengan intubasi direct laryngoscope yang dilakukan pada pasien dengan jalan napas normal, pada penelitian tersebut tidak ada penilaian derajat Cormack and Lehane 3 dan 4. ${ }^{16,17}$ Penelitian pada tindakan laringoskopi yang dilakukan pada maneken dengan rigid collar neck memiliki hasil serupa dimana tidak didapatkan derajat Cormack and Lehane 3 dan 4, namun pada penelitian ini tidak menunjukkan hal tersebut $(\mathrm{P}<0,05)$, derajat Cormack and lehane 3 didapatkan lebih tinggi menggunakan video laryngoscope VL-Scope (16,2\%) dibanding dengan video laryngoscope $\mathrm{C}$ $\operatorname{MAC}(2,7 \%){ }^{18,19,20}$

Pada penelitian lain yang membandingkan video laryngoscope $\mathrm{C}$ MAC dengan D-Blade CMAC pada simulasi maneken dengan cervical spine injury menggunakan cervical collar tidak didapatkan perbedaan bermakna secara statistik $(\mathrm{P}>0.05)$ untuk melihat Cormack and Lehane. ${ }^{17,20,21}$ Pada penelitian ini juga tidak didapatkan derajat Cormack and Lehane 3 dan 4. Meskipun pada penelitian ini kedua video laringoskop ini menggunakan bilah laringoskop dengan kelengkungan yang sama, penempatan fiksasi kamera di ujung bilah lebih baik pada video 
laringoskop C-MAC sehingga akan mempengaruhi waktu untuk melihat dan derajat Cormack Lehane. Pada penelitian Romi, ${ }^{16,22}$ yang mengatakan tidak didapatkan derajat Cormack and Lehane 3 dan 4 pada penggunaan video laringoskop pada jalan napas normal, hal ini dapat dijelaskan karena pada pasien dengan jalan napas normal dapat dilakukan manuver Sniffing position yang tidak dilakukan pada pasien dengan cedera leher yang menyebabkan meningkatnya morbiditas pada pasien tersebut, sehingga tindakan laringoskopi menggunakan video laryngoscope VLScope pada jalan napas normal untuk menilai dan melihat derajat Cormack and Lehane lebih mudah. ${ }^{23}$

Pada penelitian lain, video laryngoscope C-MAC terbukti lebih baik bila dibandingkan dengan video laryngoscope D-blade C-MAC, laringoskop Macintosh dan McCoy pada tindakan intubasi dengan simulasi maneken dengan trauma leher. ${ }^{17,24}$ Pada penelitian ini, perbedaan waktu intubasi pada maneken imobilisasi Cervical spine dengan rigid collar neck menggunakan video laryngoscope C-MAC dan VLScope berbeda bermakana, dimana ratarata waktu yang dibutuhkan untuk melakukan intubasi menggunakan video laryngoscope C-MAC 17,89 $\pm 5,9$ detik dengan waktu tercepat untuk melakukan intubasi 6 detik dam waktu terlama melakukan intubasi 37 detik sedangkan pada video laringoskop VL-Scope ratarata waktu yang dibutuhkan untuk intubasi 20,68 $\pm 5,83$ detik waktu tercepat untuk melakukan intubasi 10 detik dan waktu terlama 40 detik, hasil penelitian tersebut sama dengan penelitian Sakles, ${ }^{16,23}$ dimana penelitian ini membandingkan video laringoskop CMAC, Glidescope ${ }^{\circledR}$ dan Airtaq ${ }^{\circledR}$ pada skenario difficult airway pada maneken (imobilisasi cervical dengan hard collar pada maneken) dan easy airway pada maneken. ${ }^{7}$ Hasil dari penelitian tersebut mengatakan bahwa video laringoskop CMAC mempersingkat waktu tindakan intubasi pada maneken dengan imobilisasi cervical dengan hard collar dimana secara statistik didapatkan perbedaan bermakna dengan rata-rata waktu intubasi yang diperlukan 14 detik pada video laryngoscope C-MAC, 22 detik pada video laryngoscope Airtaq ${ }^{\circledR}$ dan 24 detik pada video laryngoscope Glidescope $^{\circledR}(p=0.002)$, sedangkan pada easy airway video laringoskop C-MAC tidak berbeda bermakna bila dibandingkan dengan video laringoskop $\operatorname{Airtaq}^{\circledR}(p>0.05)$.

Hasil penelitian ini didukung oleh penelitian Romi pada tahun 2017, dimana penggunaan video laringoskop pada jalan napas normal tidak berbeda bermakna ( $p>0.989)$. Hal tersebut tidak terjadi pada penggunaan video laringoskop yang digunakan pada simulasi imobilasi cervical spine dengan rigid collar neck khususnya video laryngoscope VL-Scope, hal ini terjadi karena letak kamera dari video laryngoscope C-MAC terfiksasi lebih baik sehingga saat tindakan intubasi pada maneken dengan imobilisasi cervical spine dengan rigid collar neck lebih baik dalam mendapatkan derajat Cormack and Lehane sehingga dapat mempersingkat waktu intubasi, sedangkan pada video laryngoscope VLScope fiksasi kamera pada ujung bilah laringoskop dilakukan secara sederhana dan kemungkinan berubah saat tindakan laringoskopi sehingga menjadi faktor penyebab dibutuhkannya waktu yang lebih lama untuk mendapatkan visualisasi laring yang lebih baik, selain hal itu handle dari video laringoskop VL-Scope yang lebih panjang dan membentur bagian dada maneken, menyulitkan residen saat memasukkan 
video laringoskop VL-Scope ke dalam mulut maneken sehingga waktu yang dibutuhkan untuk intubasi lebih lama dibanding dengan video laringoskop CMAC.

Penelitian lain di Turki mengatakan kejadian penekanan gigi secara berlebihan saat melakukan tindakan laringoskopi pada skenario Cervical Spine immobilization with hard cervical collar berbeda bermakna $(\mathrm{p}<0.03)$ dimana kejadian penekanan berlebihan terhadap gigi saat laringoskopi menggunakan video laryngoscope DBlade lebih rendah dibanding dengan video laryngoscope C-MAC. ${ }^{9}$ Sedangkan pada penelitian ini kejadian penekanan gigi secara berlebihan saat melakukan tindakan laringoskopi pada maneken imobilisasi Cervical Spine dengan rigid collar neck menggunakan video laryngoscope C-MAC dan VLScope tidak berbeda bermakna $(\mathrm{P}=1)$ dengan angka kejadian penekanan gigi secara berlebihan $2 / 35 \quad(5,4 \%)$ saat tindakan laringoskopi menggunakan video laryngoscope $\mathrm{C}$-MAC maupun VL-Scope. Hal ini dapat dijelaskan karena bentuk bilah laringoskop yang digunakan pada penelitian ini menggunakan Macintosh yang memiliki sudut yang sama sehingga saat melakukan tindakan laringoskopi kemungkinan kejadian penekanan berlebihan pada gigi akan sama. Berbeda pada penelitian yang dilakukan oleh Alper yang membandingkan C-MAC dan D-Blade dimana bilah laringoskop dari kedua laringoskop tersebut memiliki sudut kelengkungan yang berbeda sehingga pada penelitian Alper angka kejadian penekanan berlebihan terhadap gigi lebih rendah.

\section{KESIMPULAN}

Intubasi menggunakan video laryngoscope C-MAC lebih efektif pada maneken imobilisasi cervical spine dengan rigid collar neck namun angka kejadian penekanan gigi pada tindakan tersebut adalah sama.

\section{DAFTAR PUSTAKA}

1. Jain Divya, Dhankar Mandeep, Wig Jyotsna, Jain Amit. Comparison of the conventional CMAC and the D-blade CMAC with the direct laryngoscopes in simulated cervical spine injury-a manikin study. Rev. Bras. Anestesiol. 2014 Aug; 64( 4 ): 269274

2. Stroumpoulis K, Pagoulatou A, Violari M, et al. Videolaryngoscopy in the management of the difficult airway: acomparison with the Macintosh blade. Euro J Anaesthesiol.2009;26:218-22

3. Jordan, $G$ et al. Evaluation of four manikins as simulators for teaching airway management procedures specified in the Difficult Airway Society guidelines, and other advanced airway skills. Department of Anaesthesia, Royal United Hospital, Combe Park,2007. Available at: https://www.ncbi.nlm.nih.gov/pub med/17567347

4. Byhahn C, Iber T, Zacharowski K, et al. Tracheal intubation usingthe mobile C-MAC video laryngoscope for patients with a simulated difficult airway. Minerva Anestesiol. 2010;76:57783

5. Media R. Perbandingan efektivitas antara penggunaan video laryngoscope modifikasi anestesia, video laryngoscope $\mathrm{C}$ - MAC dan Direct Laryngoscope Macintosh pada intubasi rutin pasien elektif di RSUD Dr. Soetomo. [Thesis] 
Surabaya: Departemen Anestesi dan Reanimasi: Universitas Airlangga; 2017

6. Benumof JL. Preoxygenation: best method for both efficacy andefficiency. Anesthesiology. 1999;91:603-5

7. McElwain, J., Malik, M., Harte, B., Flynn, N. and Laffey, J. 2010, Comparison of the C-MAC ${ }^{\circledR}$ videolaryngoscope with the Macintosh, Glidescope ${ }^{\circledR}$, and Airtraq ${ }^{\circledR}$ laryngoscopes in easy and difficult laryngoscopy scenarios in manikins. Anaesthesia, 2010; 65: 483-489. doi:10.1111/j.13652044.2010.06307.x

8. Wijaya et al. First Clinical Evaluation of Airlangga University Self Made Video Laryngoscope During Routine and Emergency Intubation: A Preliminary Study. Poster. 2016

9. Kilıçaslan A, Topal A, Erol A, Uzun ST. Comparison of the CMAC D-Blade, Conventional CMAC, and Macintosh Laryngoscopes in Simulated Easy and Difficult Airways. Turk J Anaesthesiol Reanim. 2014 Aug; 42(4): 182-189.

10. Ong JR, et al. Comparing the performance of traditional direct laryngoscope with three indirect laryngoscopes: A prospective manikin study in normal and difficult airway scenarios. Emerg Med Australas 2011;23:606-14.

11. Arslan ZI, et al. Tracheal intubation in patients with rigid collar immobilisation of the cervical spine: A comparison of Airtraq and LMA CTrach devices. Anaesthesia 2009;64:1332-6

12. Langeron O, Cuvillon P, IbanezEsteve C, Lenfant F, Riou B, Le Manach Y. Prediction of Difficult Tracheal Intubation: Time for a
Paradigm

Change.

Anesthesiology: The Journal of the American Society of Anesthesiologists. 2012 Dec 1;117(6):1223-33

13. Gupta, Sunanda. Airway assessment: predictors of difficult airway. Indian.J.Anaesth.49(4): 257-262. 2005

14. American Society of Anesthesiologists, Inc. Lippincott Williams \& Wilkins, Inc Practice Guidelines for Management of the Difficult Airway.Anesthesiology; 98:1269-77.2003

15. Soni, Semedi, Pesta. Derajat Cormack-Lehane antara penggunaan video laryngoscope modifikasi anestesi,video laryngoscope C-MAC dan direct laryngoscope Macintosh pada intubasi rutin pasien elektif di RSUD dr.Soetomo. [Thesis] Surabaya: Departemen Anestesi dan Reanimasi: Universitas Airlangga; 2016

16. Sakles J, et al. A comparison of CMAC video laryngoscope to the Macintosh Direct Laryngoscope for Intubation in Emergency Departement. Emerg Med. 2012; 60(6):739-

748.doi:10.1016/j.annermergmed. 2012.03.031.

17. Noppen, et al. Endotracheal Intubation Using the C-MAC video laryngoscope or the Macintosh Laryngoscope: A prospective, comparative study in the ICU.Department of Anesthesiology, University Medical Center of the Johannes Gutenberg-University. Critical Care Research, 2012. Available at: http://ccforum.com/content/16/3/ R103.

18. Sakles, John C. et al. The C-MAC ${ }^{\circledR}$ Video Laryngoscope Is Superior to 
the Direct Laryngoscope for the Rescue of Failed First-Attempt Intubations in the Emergency Department. Journal of Emergency Medicine. 2015; 48(3): 280-6

19. Kamel, Atef. C-MAC Video Laryngoscopy Versus Flexible Fiberoptic Laryngoscopy in Patients with Anticipated Difficult Airway: A Randomized Controlled Trial. journal of anesthesia and patient care. 2015; 1: 101

20. Karalapillai D, Darvall J, Mandeville J, Ellard L, Graham J, Weinberg L. A review of video laryngoscopes relevant to the intensive care unit. Indian J Crit Care Med. 2014;18(7):442-452. doi:10.4103/0972-5229.136073

21. Hurford, William. The video revolution: A new view of laryngoscopy. Respiratory care 2010; 55: 1036-45
22. Healy D, et al. Comparison of the Glidescope, CMAC, Stor DCI with the Macintosh Laryngoscope During Simulated Difficult Laryngoscope: a Manikin Study. BMC Anesthesiology. 2012, 12:11. Available at:http://www.biomedcentral.com/ 1471-2253/12/11

23. Henderson JJ, Popat MT, Latto IP, Pearce AC. Difficult Airway Society guidelines for management of the unanticipated difficult intubation. Anaesthesia 2004; 59: 675-694. doi:10.1111/j.13652044.2004.03831.x

24. Goto, Yukari. Emergency Airway Management by Resident Physicians in Japan: an Analysis of Multicentre Prospective Observational Study. Acute Medicine and Surgery. 2014. 214221 